\title{
Clinical Management of Seafood Allergy
}

Carla M. Davis, MD ${ }^{\mathrm{a}}$, Ruchi S. Gupta, MD, MPH ${ }^{\mathrm{b}}$, Ozge N. Aktas, MD ${ }^{\mathrm{c}}$, Veronica Diaz, MD ${ }^{\mathrm{a}}$, Sandip D. Kamath, PhD ${ }^{\mathrm{d}}$, and

Andreas L. Lopata, PhD $^{\mathrm{d}}$ Houston, Texas; Chicago, Ill; and Townsville, QLD, Australia

\section{INFORMATION FOR CATEGORY 1 CME CREDIT}

Credit can now be obtained, free for a limited time, by reading the review articles in this issue. Please note the following instructions.

Method of Physician Participation in Learning Process: The core material for these activities can be read in this issue of the Journal or online at the JACI: In Practice Web site: www.jaci-inpractice.org/. The accompanying tests may only be submitted online at www.jaciinpractice.org/. Fax or other copies will not be accepted.

Date of Original Release: January 1, 2020. Credit may be obtained for these courses until December 31, 2020

Copyright Statement: Copyright (C) 2020-2022. All rights reserved.

Overall Purpose/Goal: To provide excellent reviews on key aspects of allergic disease to those who research, treat, or manage allergic disease.

Target Audience: Physicians and researchers within the field of allergic disease.

Accreditation/Provider Statements and Credit Designation: The American Academy of Allergy, Asthma \& Immunology (AAAAI) is accredited by the Accreditation Council for Continuing Medical Education (ACCME) to provide continuing medical education for physicians. The AAAAI designates this journal-based CME activity for 1.00 AMA PRA Category 1 Credit $^{\mathrm{TM}}$. Physicians should claim only the credit commensurate with the extent of their participation in the activity.

List of Design Committee Members: Carla M. Davis, MD, Ruchi S. Gupta, MD, MPH, Ozge N. Aktas, MD, Veronica Diaz, MD, Sandip D.
Kamath, $\mathrm{PhD}$, and Andreas L. Lopata, PhD (authors); Scott H. Sicherer, MD (editor)

Learning objectives:

1. To distinguish characteristics of shellfish allergy, fish allergy, and seafood poisoning

2. To recognize aspects of cross-reactivity regarding seafood

3. To order appropriate laboratory tests to distinguish shellfish from fish allergy

Recognition of Commercial Support: This CME has not received external commercial support.

Disclosure of Relevant Financial Relationships with Commercial Interests: C. M. Davis has grants/contracts from the National Institutes of Health Rare Disease Network, National Institute of Allergy and Infectious Diseases, Regeneron Pharmaceuticals, Allakos, DBV Technologies, Inc, Aimmune Therapeutics, Inc, and FARE; and is a consultant for Moonlight Therapeutics, Inc. R. S. Gupta has received grants from the National Institute of Health (grant nos. R21 ID \#AI135705, R01 ID\#AI130348, and U01 ID \#AI138907), Rho, Inc, Stanford Sean N. Parker Center for Allergy Research, Aimmune Therapeutics, United Health Group, Thermo Fisher Scientific, Genentech, and the National Confectioners Association; and serves as a medical consultant/advisor for Before Brands, Kaléo, Inc, Genentech, ICER, DOTS Technology, FARE, and DBV Technologies. The rest of the authors declare that they have no relevant conflicts of interest. S. H. Sicherer reports grants from NIAID; and personal fees from American Academy of Allergy, Asthma and Immunology, UpToDate, and Johns Hopkins University Press, outside of the submitted work.
Seafood plays an important role in human nutrition and health. A good patient workup and sensitive diagnostic analysis of IgE antibody reactivity can distinguish between a true seafood allergy and other adverse reactions generated by toxins or parasites

aTexas Children's Hospital Food Allergy Program, Baylor College of Medicine, Texas Children's Hospital, Houston, Texas

${ }^{\mathrm{b}}$ Center for Food Allergy and Asthma Research, Northwestern University Feinberg School of Medicine and Ann \& Robert H. Lurie Children's Hospital of Chicago, Chicago, Ill

${ }^{\mathrm{c}}$ Department of Pediatrics, University of Illinois College of Medicine at Chicago, Chicago, Ill

${ }^{\mathrm{d}}$ College of Public Health, Medical and Veterinary Sciences, Australian Institute of Tropical Health and Medicine, Molecular Allergy Research Laboratory, James Cook University, Townsville, QLD, Australia

Conflicts of interest: C. M. Davis has grants/contracts from Regeneron Pharmaceuticals, Allakos, DBV Technologies, Inc, Aimmune Therapeutics, Inc, and Food Allergy Research and Education; and is a consultant for Moonlight Therapeutics, Inc. R. S. Gupta has received grants from the National Institute of Health (grant nos. R21 ID \#AI135705, R01 ID\#AI130348, and U01 ID \#AI138907), Rho,Inc, Stanford Sean N. Parker Center for Allergy Research, Aimmune Therapeutics, contaminating ingested seafood. The 2 most important seafood groupings include the fish and shellfish. Shellfish, in the context of seafood consumption, constitutes a diverse group of species subdivided into crustaceans and mollusks. The prevalence of

United Health Group, Thermo Fisher Scientific, Genentech, and the National Confectioners Association; and serves as a medical consultant/advisor for Before Brands, Kaléo, Inc, Genentech, ICER, DOTS Technology, FARE, and DBV Technologies. The rest of the authors declare that they have no relevant conflicts of interest.

Received for publication August 31, 2019; revised manuscript received and accepted for publication October 23, 2019.

Corresponding author: Carla M. Davis, MD, 1102 Bates Ave, MC 330.01, Houston TX, 77030. E-mail: carlad@bcm.edu. 2213-2198

(C) 2019 The Authors. Published by Elsevier Inc. on behalf of the American Academy of Allergy, Asthma \& Immunology. This is an open access article under the CC BY-NC-ND license (http://creativecommons.org/licenses/by-nc-nd/4.0/). https://doi.org/10.1016/j.jaip.2019.10.019 
Abbreviations used

OFC-oral food challenge

PPT-prick-to-prick testing

SPT-skin prick test

shellfish allergy seems to be higher than that of fish allergy, with an estimate of up to $3 \%$ in the adult population and fin fish allergy prevalence of approximately $1 \%$. Clinical evaluation of the seafood-allergic patient involves obtaining a detailed history and obtaining in vivo and/or in vitro testing with careful interpretation of results with consideration of cross-reactivity features of the major allergens. Oral food challenge is useful not only for the diagnosis but also for avoiding unnecessary dietary restrictions. In this review, we highlight some of the recent reports to provide solid clinical and laboratory tools for the differentiation of fish allergy from shellfish allergy, enabling best treatment and management of these patients. (C) 2019 The Authors. Published by Elsevier Inc. on behalf of the American Academy of Allergy, Asthma \& Immunology. This is an open access article under the CC BY-NC-ND license (http://creativecommons.org/ licenses/by-nc-nd/4.0/). (J Allergy Clin Immunol Pract 2020;8:37-44)

Key words: Fish allergy; Shellfish allergy; Crustacean; Mollusk; Diagnosis of fish allergy; Skin prick test; Oral food challenge

\section{INTRODUCTION}

Seafood plays an important role in human nutrition and health. The growing international trade in seafood species and products has added to the popularity and frequency of consumption of various seafood products across many countries. However, seafood can also provoke serious adverse reactions in susceptible individuals. ${ }^{1,2}$

Adverse reactions to seafood can be classified into 3 categories, on the basis of underlying mechanisms: (1) immunologic reactions, including $\operatorname{IgE}$ and non- $\operatorname{IgE}$ allergic reactions such as food protein-induced enterocolitis syndrome ${ }^{3}$; (2) toxic reactions, including marine biotoxins ${ }^{4}$; and (3) food intolerance. ${ }^{5}$ Adverse reactions due to toxins and/or food intolerance often resemble clinical symptoms of seafood allergy. A good patient workup and sensitive diagnostic analysis of $\mathrm{IgE}$ antibody reactivity can distinguish between a true seafood allergy and other adverse reactions.

Allergic symptoms after ingestion can occur within minutes and range from nausea, vomiting, urticaria to asthma exacerbation and anaphylaxis. Respiratory reactions along with oral allergy syndrome are very often reported in seafood allergy, but frequency might vary with geography and study population. ${ }^{6,7}$ Reactions are usually reported within 2 hours; however, latephase reactions are described particularly among people allergic to snow crab, cuttlefish, limpet, and abalone. ${ }^{8}$ Crustacean and fish, similar to nuts, are among the most common causes of anaphylaxis and death from food allergy. ${ }^{9-12}$

Sensitization and subsequent reactions occur most frequently upon ingestion; however, they can also occur because of skin contact or inhalation of aerosolized proteins generated during cooking or processing in factories and domestic environment. ${ }^{13}$
The prevalence of shellfish allergy seems to be higher than that of fish allergy, with an estimate of up to $3 \%$ in the adult population. ${ }^{2,12}$ Fin fish allergy occurs in approximately $1 \%$ of adults. Shellfish allergy is of particular importance in the Asia-Pacific region, with selfreported rates of shellfish allergy ranging from $0.9 \%$ to $1.19 \%$ in children younger than 7 years to $5.12 \%$ to $7.71 \%$ in adolescents and adults in Hong Kong, Philippines, and Singapore. ${ }^{14,15}$ Similarly, a cross-sectional study on doctor-diagnosed seafood allergy in Vietnam confirmed the high prevalence among children up to age 6 years. Crustacean was the predominant allergy-inducing food (3.8\%), followed by fin fish (1.2\%) and mollusk (1.0\%) in a study population of more than 8600 participants. ${ }^{16}$ Unlike most other food allergies, seafood allergy is thought to persist for life in up to $90 \%$ of patients, with a similar trend also observed in peanut allergy. ${ }^{1}$

The 2 most important seafood groupings include the fish and shellfish (see Figure 1). Within the large group of fish, most reported allergies are to bony fish, whereas cartilaginous fish (rays and sharks) seem to be of lower allergenicity. ${ }^{18}$ Shellfish, in the context of seafood consumption, constitutes a diverse group of species subdivided into crustaceans and mollusks. Crustaceans, including shrimp, crab, and lobster, are classified as arthropods together with mites, spiders, and insects. ${ }^{19,20}$ This might provide an explanation of the observed molecular and clinical crossreactivity. The term "shrimp" and "prawn" are often used interchangeably in the commercial as well as scientific sector, with the latter term used more in the United Kingdom and Australia. ${ }^{21}$ However, there are anatomical differences between the 2 animals. In general, prawns are bigger in size than shrimp. The most prominent difference is in the carapace. In shrimp, the second segment of the shell overlays the first and the third, thereby giving them the typical bend in their body. However, in prawns, the segments of the shell overlap each other front to back, thereby imparting a lesser bend to the body.

Patients with seafood allergy may fail to identify the offending seafood species, often as a result of confusion regarding the diversity of seafood consumed and the different common names used to describe seafood. In addition, fraudulent substitution and/or mislabeling of produce have been demonstrated for various seafood species, most frequently for fish. ${ }^{22}$ Because there is specificity to seafood allergy, with some patients allergic to only fish and not shellfish and some patients allergic to crustaceans and not mollusks, identification of the specific allergy is important for further management of the disease.

The group of mollusks is a large and diverse cluster, further subdivided into the classes bivalve, gastropod, and cephalopod, including several important consumed species such as mussels, oysters, abalone, snails, and squid (calamari). The mollusks and crustaceans seem to include similar but also different allergens important in distinguishing allergic sensitization to one or the other group. Several panallergens are characterized in detail, including tropomyosin and arginine kinase, responsible for clinical cross-reactivity with other frequent invertebrate allergen sources, comprising mites, insects, and parasites ${ }^{1}$ (see Figure 1). However, additional shellfish allergens have been characterized, ${ }^{23}$ making component-resolved diagnosis possible in the near future. ${ }^{24,25}$ Most shellfish allergens, including the major allergen tropomyosin, are known to be heat-stable. Current in vitro diagnostic tools for shellfish allergy include a mix of raw or heated shellfish extracts to account for sensitization and allergy to heat-labile as well as heat-stable shellfish allergens. ${ }^{24,25}$ 


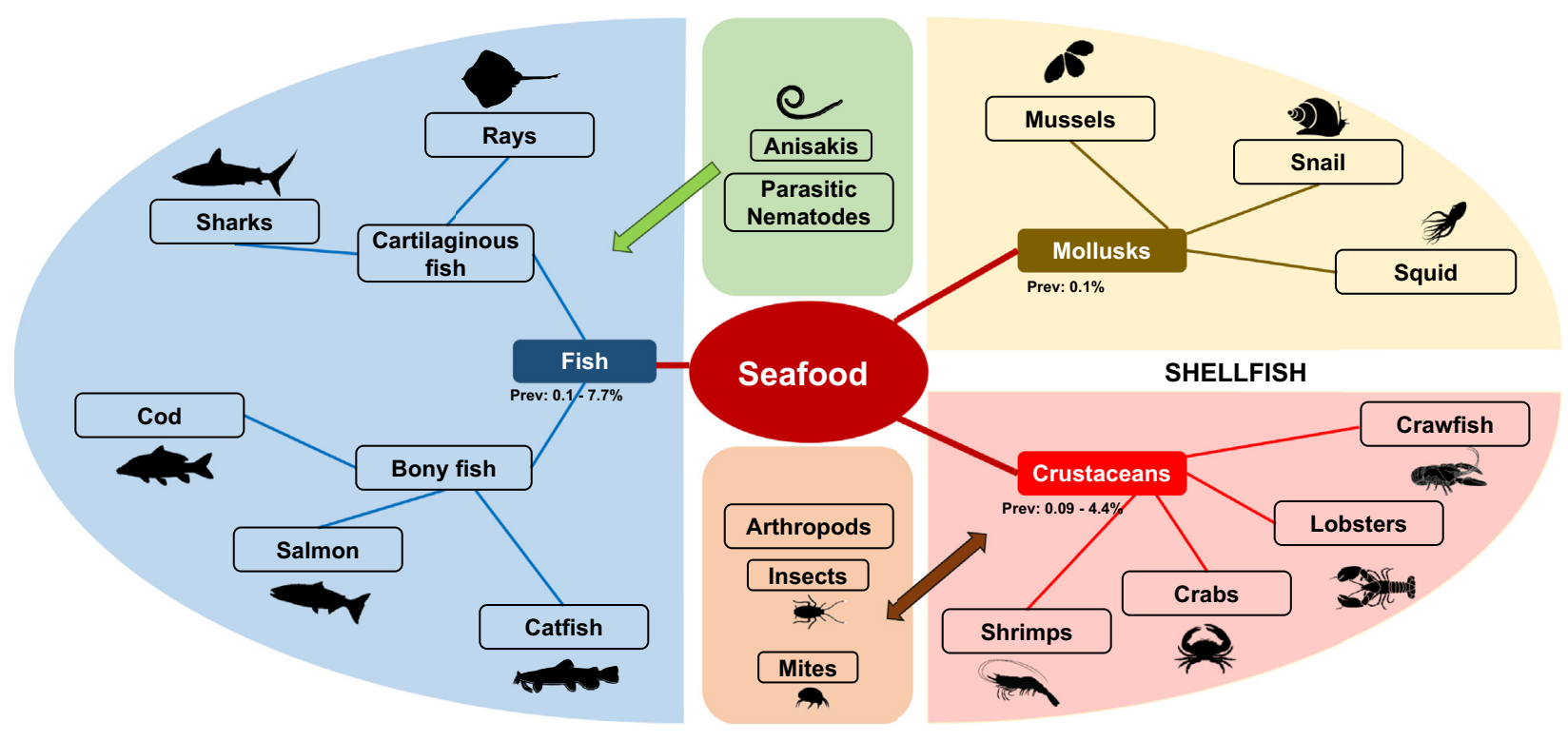

FIGURE 1. Edible seafood can be broadly categorized as vertebrates (fish) and invertebrates (shellfish). Edible fish species are mainly grouped as cartilaginous fish and bony fish. The term shellfish includes species from the phylum molluska and subphylum crustacea. Closely related arthropods such as insects and mites (brown arrow) can contain cross-reactive allergens. Nematodes such as Anisakis are commonly found in edible fish (green arrow); however, they have shared allergens with crustaceans. Allergy prevalence values (\%) stated for bony fish, crustaceans, and mollusks are derived from self-reported, doctor-diagnosed, or challenge-proven studies.

In contrast, the major fish allergen parvalbumin seems to be very different between many fish species, reflected in "monosensitization" to specific groups, such as salmon and trout. ${ }^{26-29}$ Additional allergens seem to be present only in raw fish (enolase and aldolase), ${ }^{29}$ whereas some other allergens are highly concentrated in the skin (collagen and gelatin). ${ }^{1,30}$ A study among 9 fish species identified codfish, salmon, pollock, and herring as the most allergenic and cross-reacting species, whereas halibut, flounder, tuna, and mackerel seem to be less allergenic. ${ }^{27}$ In addition, the marine roundworm Anisakis, contaminating marine fish, can cause allergic sensitization, resulting often in misdiagnosis as allergy to the fish. ${ }^{31,32}$

In this review, we will highlight some of the recent reports to provide solid clinical and laboratory tools for the differentiation of fish allergy from shellfish allergy, enabling best treatment and management of these patients.

\section{CASE PRESENTATION: PEDIATRIC SHELLFISH ALLERGY}

A 16-year-old female presented with allergic rhinitis to dust mite and cat. She had several severe episodes of anaphylaxis to shellfish. The first documented reaction involved tongue and lip swelling with pruritus 20 minutes after eating shrimp, which selfresolved in 24 hours. The second reaction was a more severe episode, with periorbital, lip, and tongue swelling along with hives 30 minutes after eating rice with shrimp. Epinephrine and diphenhydramine were given at home by emergency medical services. She did not go to the emergency department despite mild persistent facial swelling, because of severe inclement weather. Her facial swelling worsened and she developed new-onset shortness of breath, which prompted her to seek medical care after several days.

Because of concerns for late-phase anaphylaxis and airway obstruction, she was admitted to the pediatric intensive care unit where she was treated with solumedrol, ranitidine, and diphenhydramine. The Allergy and Immunology service was consulted because of severe late-phase anaphylaxis. The workup was significant for a total $\mathrm{IgE}$ level of $1060 \mathrm{kU} / \mathrm{L}$, with levels of specific $\operatorname{IgE}$ of $15.6 \mathrm{kU} / \mathrm{L}$ for crayfish, of $13.8 \mathrm{kU} / \mathrm{L}$ for shrimp, of $1.44 \mathrm{kU} / \mathrm{L}$ for sea crawfish/langust (spiny lobster), of $7.93 \mathrm{kU} /$ $\mathrm{L}$ for lobster, of $0.56 \mathrm{kU} / \mathrm{L}$ for crab, and of $0.47 \mathrm{kU} / \mathrm{L}$ for anchovy. All other fish and all mollusk test results were negative $(<0.35 \mathrm{kU} / \mathrm{L})$. She had normal C1 esterase nonfunction level of $38 \mathrm{mg} / \mathrm{dL}$ and function inhibitor $(80 \%,>60 \%$ is normal), ruling out hereditary angioedema.

A second episode of anaphylaxis happened 1 hour after eating prepackaged $B B Q$ chicken wings and was significant for hives, lip, tongue, throat, and hand swelling. She required intramuscular epinephrine twice and diphenhydramine and was admitted for observation given the severity of the reaction. Despite intravenous steroids, diphenhydramine, and ranitidine, facial and throat swelling worsened 5 to 6 hours later. She required a third dose of intramuscular epinephrine and transfer to the pediatric intensive care unit for an epinephrine drip to control the swelling. There were no reported episodes of hypotension. She improved within 24 hours and had mild residual lip swelling on discharge. It was later noted that the BBQ wing sauce contained shellfish, fish, artichoke, and anchovies. Repeat testing showed a total IgE level of $647 \mathrm{IU} / \mathrm{mL}$, with levels of specific IgE of $0.44 \mathrm{kU} / \mathrm{L}$ for artichoke, of $0.49 \mathrm{kU} / \mathrm{L}$ for anchovy, and of less than $0.35 \mathrm{kU} / \mathrm{L}$ for both salmon and codfish.

Her third episode of anaphylaxis occurred 30 minutes after eating a cheese and sausage pastry from the school cafeteria where fish and shellfish were being prepared. Despite receiving intramuscular epinephrine and diphenhydramine in school, the swelling and hives worsened when she reached the emergency department. A second dose of epinephrine was given along with solumedrol, pantoprazole, and a normal saline bonus. Tryptase level on admission was $3.1 \mu \mathrm{g} / \mathrm{L}$. Specific IgE level for wheat, beef, pork, chicken, and milk were all less than $0.35 \mathrm{ku} / \mathrm{L}$. Her 
symptoms improved and she was discharged home the next day without any late-phase reactions documented.

Shellfish allergy although more common in adults than in children is an important food allergen to be aware of in the pediatric population. ${ }^{10,33-35}$ In a pediatric US prevalence study by Gupta et al, ${ }^{35} 8 \%$ of children had food allergies, 38.7\% with severe reactions, of which shellfish was the third most common. ${ }^{35}$ In a prevalence study among children in Vietnam, up to $7 \%$ reported diagnosed food allergy, with crustacean, fish, and mollusk being the 3 most common food allergens. ${ }^{16}$ Shellfish allergy tends to present with anaphylaxis and episodes can be lifethreatening. ${ }^{1,34}$ Data from the National Electronic Injury Surveillance System in the United States showed that 24\% of emergency department visits for anaphylaxis were seen in children 6 years or older, with shellfish being the most common culprit. ${ }^{11}$ Furthermore, shellfish allergy is now the leading cause of death from food anaphylaxis in Australia, derived from the Australian Bureau of Statistics. ${ }^{36}$

This case highlights the importance of creating awareness of potential cross-contamination and how small doses of aerosolized allergen can be enough to cause symptoms of an allergic reaction and even anaphylaxis. ${ }^{37-40}$ In fact, sensitization to food allergens via inhalation is suggested to be a distinct form of food allergy. ${ }^{39,41,42}$ Traditionally, sensitization to ingested food is termed class 1 food allergy, while class 2 food allergy is commonly observed following allergic sensitization to pollen aeroallergens, due to cross-reactive allergens. However, over recent years what has become evident is that many food allergens can act as a primary sensitizer through inhalation at the workplace, causing occupational allergies. Affected individuals experience mainly respiratory symptoms, usually without associated symptoms after ingestion of the offending food, and the term class 3 food allergy is proposed. ${ }^{43}$

Although there is not much data on crustacean and mollusk allergy cross-reactivity, many physicians recommend avoidance of both because of the risk of cross-contamination. ${ }^{33}$ Although cross-reactivity is common in shellfish-allergic patients $(75 \%)$, studies have shown that crustacean-allergic patients are not always allergic to mollusks, which could be a potential source of protein for a child's diet. ${ }^{12,33}$ Of note, she was also allergic to house-dust mites, known to cause clinical cross-sensitivity due in most part to Pen a 1 IgE-binding regions of the tropomyosin protein. ${ }^{44}$ In addition, her uncontrolled allergic rhinitis potentially contributed to her symptoms. ${ }^{33,37}$ Her case also features recurrent late-phase anaphylaxis, which, although rare, is potentially fatal if not recognized promptly. ${ }^{8-11}$

\section{CASE PRESENTATION: ADULT FISH ALLERGY}

A 25-year-old man with no significant past medical history presented to the emergency room because of progressive rash and facial swelling concerning for a food-related adverse reaction. Three days ago, at dinner he developed an itchy rash on the face, quickly progressing to his neck, as well as some swelling on the lips and face. Upon detailed history taking, he stated eating a meal containing fish in the restaurant 3 hours before presentation, and denied having associated symptoms including gastrointestinal (eg, nausea, vomiting, diarrhea, and abdominal pain), respiratory (eg, cough, shortness of breath, and wheezing), and cardiovascular (tachycardia and hypotension). He had never experienced similar symptoms in the past. Past medical history was remarkable only for a diagnosis of eczema in childhood. He did not use any medications and did not have any known allergies. He had a younger cousin with multiple seafood allergies including fish and crustacean allergy as well as peanut allergy. He stated he did not usually eat fish or other types of seafood and that it had been 6 months since he had last been to a seafood restaurant.

Physical examination was remarkable for urticarial rash on the face, neck, and anterior chest and mild periorbital and perioral angioedema. The patient was given a dose of cetirizine and discharged home after resolution of the symptoms and a 6-hour observation period in the emergency room with a follow-up appointment with the primary care physician who then referred the patient to the Allergy-Immunology Clinic for further evaluation of food allergy.

Following a detailed review of clinical history and complete physical examination in the Allergy-Immunology Clinic, specific IgE levels to fish including codfish, halibut, mackerel, walleye pike, salmon, trout, and tuna, and shellfish including clam, crab, lobster, oyster, scallop, and shrimp, were tested and resulted positive for codfish $(2.36 \mathrm{kU} / \mathrm{L})$, halibut $(0.7 \mathrm{kU} / \mathrm{L})$, and salmon (1.98 kU/L). To confirm the diagnosis, an oral food challenge (OFC) was performed with all 3 fish and resulted in urticaria, perioral angioedema, and mild abdominal discomfort with codfish and salmon, but not with halibut. After confirmation of salmon and codfish allergy, intramuscular epinephrine injection was prescribed to the patient with instructions to avoid salmon and codfish in his diet.

\section{Evaluation of the seafood-allergic patient in vivo}

History. A detailed history including time and duration of the reaction, type of foods/medications consumed 6 to 8 hours before the reaction including specific fish/shellfish species, location of the event, symptom characteristics involving skin/mucosa, gastrointestinal, cardiovascular, respiratory, and neurologic system, medical care given and treatment administered, timing of resolution of symptoms, recurrence of symptoms after initial resolution, prior history of a similar reaction, past medical history of allergic conditions including dust mite or cockroach allergy, and family history of allergic diseases is essential to diagnose seafood allergies. It allows clinicians to understand and better characterize the etiology and characteristics of the reaction and help inform further confirmatory allergy testing. Cross-reactivity between and among fish and shellfish is also crucial to consider because at least one-third of seafood-allergic patients report multiple seafood allergies. ${ }^{2,45}$ Cross-reactivity is shown to be more common among shellfish allergies $(75 \%)^{46-49}$ than among fish allergies (29\%-67\%). ${ }^{45,46,49-53}$ Therefore, it is essential to obtain a thorough history regarding complaints and symptoms with all other types of seafood that might serve as a clue to understand clinical cross-reactivity between and among fish and/or shellfish species (see Figure 2).

Skin prick testing and prick-to-prick testing. Skin prick test (SPT) is a common in vivo procedure to help understand sensitivity to food allergens including fish and shellfish. The procedure involves applying drops of allergen extracts as well as the positive (histamine) and negative (usually $0.9 \%$ saline or $50 \%$ glycerol saline) control solutions to the forearm or back, usually with the help of a lancet. Following 15 to 30 minutes of allergen application to the skin, wheal sizes are measured, with the mean of the longest diameter of the wheal and the longest perpendicular diameter. Another type of skin testing is prick-to- 


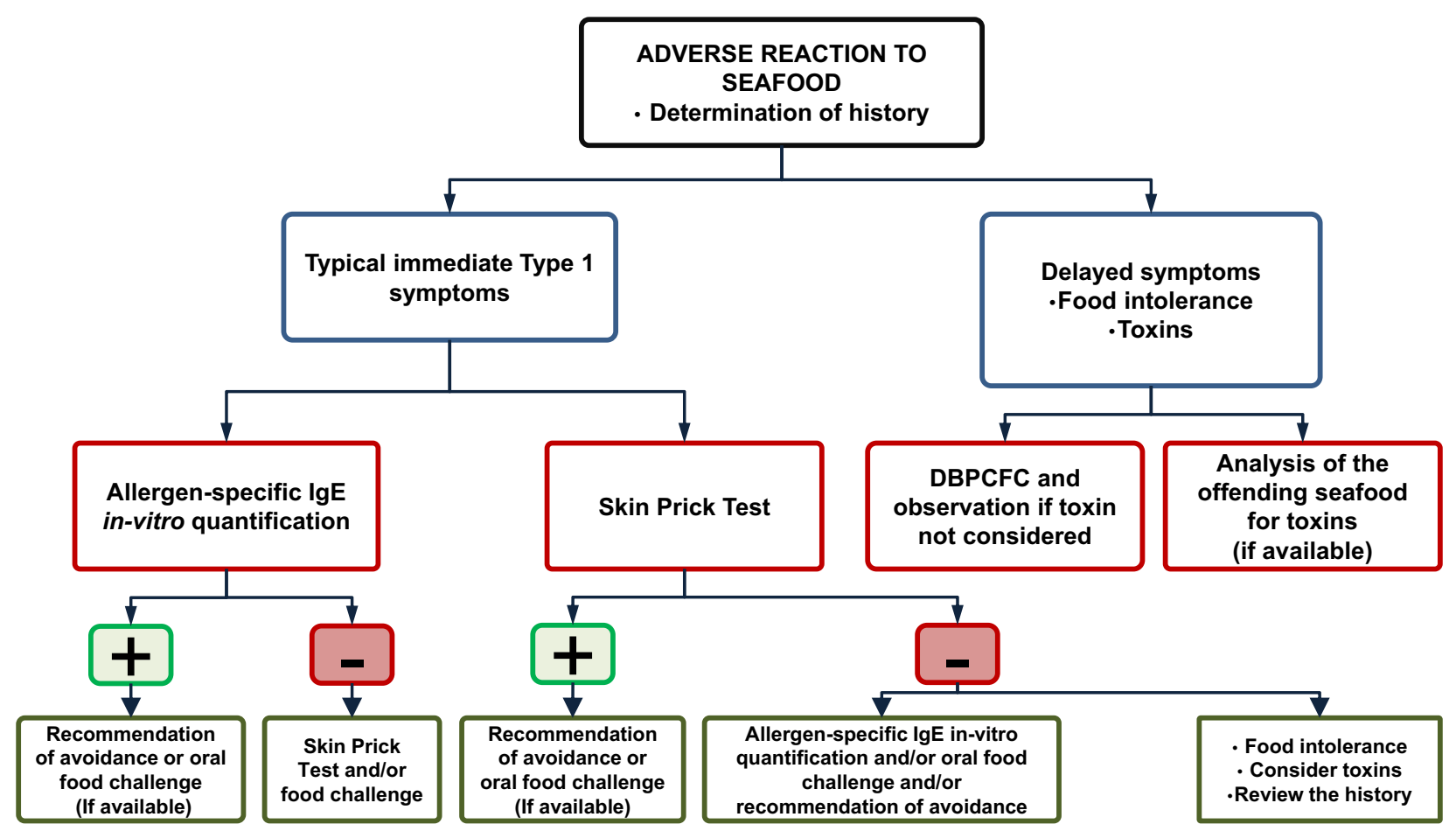

FIGURE 2. Diagnostic algorithm to distinguish and diagnose IgE-mediated allergy, food intolerance, and toxic adverse reactions to seafood. $\triangle B P C F C$, Double-blind placebo-controlled food challenge.

prick testing (PPT), where the tester first pricks the fresh food and then pricks the skin for allergen exposure. PPT is not a standardized method of testing. Medications such as antihistamines, beta-blockers, phenothiazine, and antidepressants may lead to false-negative results, and thus should be avoided before skin testing. ${ }^{54}$

Previous studies show low risk of severe allergic reaction during SPT or PPT. ${ }^{52-54}$ There are few case studies reporting anaphylaxis during these tests that mostly presented with testing 4 or more fish allergens simultaneously. ${ }^{55-61}$ Young age, ${ }^{55,56,60}$ active eczema, ${ }^{56,60}$ previous history of anaphylaxis, ${ }^{55}$ and PPT with fresh foods ${ }^{55,56,62}$ were risk factors for developing a generalized reaction or anaphylaxis during the test and should be considered while performing skin testing in daily practice. Overall, skin testing is safe to perform under surveillance of a certified provider; thus, the low risk of anaphylaxis reported in the literature should not create hesitation regarding the decision of performing a skin test. In addition, SPT has been widely used to aid the diagnosis of food allergies, but clinicians should keep in mind that clinical reactivity does not correlate directly with the level of reactivity or wheal size. ${ }^{63-66}$ Furthermore, it has been demonstrated for fish SPTs that some commercial preparations lack some of the important fish allergens, potentially leading to false-negative outcomes. ${ }^{21}$

Allergen specific IgE in vitro testing. Serum specific IgE testing is also a commonly used in vitro method of determining the presence of seafood specific IgE (sensitization) and the potential for clinical reactivity to specific fish or shellfish. The combination of a characteristic clinical history of an allergic reaction with a level of allergen specific IgE or SPT is a foundation of food allergy diagnosis (see Figure 2). Studies of the clinical value of seafood specific IgE testing are limited. ${ }^{67}$ Studies have shown that the efficacy for confirming crustacean allergy varies, with in-house measurements of IgE to the major shrimp allergen tropomyosin being superior to commercial $\operatorname{IgE}$ testing using whole shrimp protein and skin prick testing $(88.5 \%, 74.2 \%$, and $65.7 \%$, respectively). ${ }^{68}$ Positive predictive values were low for SPTs $(33.3 \%)$ and measurement of IgE to shrimp (41.6\%) compared with positive predictive values for $\operatorname{IgE}$ to shrimp tropomyosin $(71.4 \%){ }^{68}$ The specificity and clinical predictive value of ImmunoCAP specific IgE testing for shrimp is best in patients without dust mite allergy. ${ }^{68,69}$ In one study, a shrimp specific IgE level of more than $3.55 \mathrm{kU}_{\mathrm{A}} / \mathrm{L}$ showed $100 \%$ sensitivity for the diagnosis of shrimp allergy in patients not allergic to dust mite. ${ }^{69}$ This is evidence that component-resolved diagnosis could improve the diagnostic capability of serum specific IgE testing in shellfish allergy. ${ }^{70}$

A study of codfish specific IgE levels in challenge-proven codfish-allergic patients determined that $20 \mathrm{kU} / \mathrm{L}$ is highly predictive of clinical allergy. ${ }^{71}$ In addition, patients anaphylactic to pilchard or anchovy have been described to have specific IgE levels as low as $1 \mathrm{kU} / \mathrm{L},{ }^{71}$ and most patients allergic to bony fish tolerate ray, a cartilaginous fish, because of the low allergenicity of its $\alpha$-parvalbumin. ${ }^{18}$ Studies are needed to determine the specific $\mathrm{IgE}$ values predictive of clinical allergy for commonly ingested fish species.

Interpretation of serum IgE test results is highly dependent on the allergen content, potency, and stability of the allergen extracts. The current commercial SPT solutions and IgE quantification assays for shellfish and fish are produced from variable heat-treated or raw extracts. Recent comparative immunologic studies on different commercial SPTs confirmed the immense allergenic variability, resulting in false-negative patient evaluation. ${ }^{68,69,71-73}$ 
For instance, currently available IgE testing for prawns was shown to result in more than $25 \%$ of patients being missed. ${ }^{68,69,71,72}$ Although the use of the major shrimp allergen tropomyosin has been shown to have clinical utility in diagnosis, ${ }^{74}$ it is not currently commercially available. Therefore, food challenges are considered essential to the diagnosis of shellfish allergy, especially in cases in which clinical cross-reactivity with other allergens such as dust mites, cockroaches, and edible insects may account for positive serum $\operatorname{IgE}$ results. ${ }^{74-76}$

The interpretation of the results of specific $\operatorname{IgE}$ testing to seafood must incorporate the understanding that relevant seafood allergens may not be included in the extract used for the immunoassay. Twenty allergenic proteins groups within the 3 distinct seafood groups-crustacean, mollusks, and fish-have been characterized biomolecularly. ${ }^{73,77}$ For instance, the major allergens of shrimp are tropomyosin, arginine kinase, myosin light chain, sarcoplasmic calcium-binding protein, hemocyanin, and troponin C. ${ }^{26,74,75}$ The major allergens of fish are parvalbumin, tropomyosin, collagen, aldolase A, $\beta$-enolase, and vitellogenin. ${ }^{21,27}$ Many allergen isoforms have been characterized in different species, with more than 72 seafood allergens now being registered with the International Union of Immunological Societies (WHO/IUIS Allergen Subcommittee; 41 in crustacean, 25 in fish, and only 6 in mollusk). Although the immunologic cross-reactivity between fish and shellfish allergens has not been demonstrated conclusively, panallergens in seafood allergy, including parvalbumin and tropomyosin, have the potential to induce immunologic and clinical cross-reactivity. ${ }^{73}$ The basophil activation test has not been studied extensively in seafood allergy, but it has been shown to correlate with severity of reactions in shellfish and fish challenge. However, it is currently not readily available for routine testing. ${ }^{18}$

Advances in immunoproteomics enable the comprehensive in vitro analysis of individual sensitization profiles with purified and recombinant allergens. ${ }^{70,73} \mathrm{~A}$ recent study on the allergenicity of the Pacific oyster used a combined chemical, bioinformatic, and immunoproteomic analysis to identify more than 20 allergenic proteins, filling a gap in the current management of patients at high risk of concurrent reactivity to diverse allergen sources. $^{23}$ Development of component-resolved diagnosis reagents would allow the identification of diagnostic patterns, facilitating better management of prawn allergy. Componentresolved diagnosis is already applied in the ImmunoCAP assay range or the ISAC allergen microarray (Thermofisher, Waltham, MA), a multiplex assay. ${ }^{67}$ Specific fish and shellfish allergen $\operatorname{IgE}$ assays would assist in the identification of children and/or adults at risk of severe clinical reactions and persistent seafood allergy.

Oral food challenge. OFC is a reliable in vivo test to confirm food allergies in which incremental amounts of a suspected allergenic food are introduced to the patient to evaluate its potential to cause an adverse reaction. OFCs can be open, singleblind, or double-blind placebo-controlled, the latter being the criterion standard for diagnosis. It can be performed for patients of any age and is especially useful when there is uncertainty regarding the type of food eliciting the adverse reaction. While performing OFC, fish and shellfish can be masked in another tolerated ground meat or fruit juice to avoid the smell or taste of the seafood ingested for blind procedures. ${ }^{78-81}$ Exclusion criteria for an OFC are pregnancy, unstable asthma, medications that interfere with the treatment of a challenge-induced allergic reaction, such as beta-blockers, or confounding medical conditions that might interfere with the outcome including chronic urticaria, symptomatic allergic rhinitis, severe uncontrolled asthma, and acute infection. ${ }^{78}$ OFC should not be performed if a patient is on prolonged systemic high-dose steroids, omalizumab, or other systemic immunosuppressants that might confound the interpretation of the test result. ${ }^{78}$ Of note, nonsteroidal antiinflammatory drugs, angiotensin-converting enzyme inhibitors, alcohol, and antacids can elicit a response with increased reactivity in susceptible patients. ${ }^{79,80}$ Beta-blockers should be avoided because of safety concerns because epinephrine might be required to control the reaction during the OFC. ${ }^{80}$

OFC is useful not only for the diagnosis but also for avoiding unnecessary dietary restrictions. Recent studies show that some patients with fish allergy may tolerate certain fish types. ${ }^{18,81,82}$ For instance, in a small group of patients $(\mathrm{N}=35)$ undergoing OFC with codfish, salmon, and mackerel, $54 \%$ of participants were partially tolerant, characterized by symptoms to 1 or 2 fish allergens although nearly all participants had sensitization to all 3 fish extracts. ${ }^{81}$ Thus, complete avoidance of fish in patients with fish allergy may not be necessary in selected cases, and further research is needed to understand the risk factors of developing a reaction to multiple fish types as well as partial tolerance in fish allergy.

\section{Nonimmunologic adverse reactions to seafood}

Adverse clinical reactions to seafood can also be generated by toxins or parasites contaminating the ingested seafood. Seafood is responsible for at least 1 in 6 food poisoning outbreaks in the United States, and the proportion is even higher in Japan. ${ }^{83}$ Seafood toxins are very stable, and different food preparation methods do not reduce toxicity.

The 2 most well-described fish-related adverse reactions are scombroid and ciguatera poisonings. ${ }^{84,85}$ The former occurs after eating fish that has been improperly refrigerated. Bacteria convert the amino acid histidine into histamine, generating allergy-like clinical reactions. Symptoms commence within 30 minutes and include hives, flushing, nausea, and even anaphylaxis. Fish species commonly involved include mackerel, tuna, mahi mahi, and marlin. ${ }^{84}$ Scombroid poisoning typically resolves within 12 to 48 hours with no long-term sequelae. ${ }^{84}$

In contrast, ciguatera poisoning is caused by algae-derived toxins, consumed by fish via the food chain. Ciguatera toxin causes symptoms that occur within 1 to 6 hours of ingesting fish with the toxin and can last for days, months, or years. ${ }^{85-87}$ Clinical symptoms may include gastrointestinal, cardiovascular, and neurological reactions, affecting up to 50,000 individuals annually. ${ }^{88}$ Neither scrombroid nor ciguatera toxins are affected by heating or cooking the affected fish. ${ }^{86,87}$ Marine fish are often contaminated with the parasite Anisakis and on ingestion can cause zoonotic infection (anisakiasis), reported worldwide. Infection with live Anisakis is associated with abdominal pain, nausea, and diarrhea and can lead to eosinophilia and formation of gastrointestinal granulomas. Reinfection can lead to systemic allergic reactions, making Anisakis an important source of hidden allergens in seafood. ${ }^{89,90}$

Shellfish can also cause food poisoning that can be generated by other toxins. A significant contributor is the so-called red tides, where large algae blooms of small dinoflagellates are taken up by filter-feeding shellfish. Most frequently, mussels and oysters are affected. Some neurotoxins derived from paralytic 
shellfish poisoning, blocking cellular sodium channels, account for most human fatalities through algae-derived toxins. ${ }^{85,88}$

However, frequently the source of bacterial and viral contamination of shellfish is the harvest from polluted waters. Different vibrio strains as well as Listeria and Salmonella species have been implicated as well as small round-structured viruses and Norwalk virus. Although the clinical presentation often includes gastrointestinal symptoms, these can occur several hours after consumption, similar to allergic reactions. ${ }^{91}$

\section{CONCLUSIONS}

Seafood allergies include shellfish (crustaceans and mollusks) and fish, and can cause severe clinical reactions ranging from immunologic toxic to infectious etiologies. Adults are most commonly affected, but children can also present with seafood allergy. Clinical management requires a detailed history coupled with careful diagnostic testing through skin prick testing, serum specific $\operatorname{IgE}$, and, in appropriate cases, an OFC. After diagnosis, the current treatment of seafood allergy is strict avoidance.

Nonimmunologic reactions to seafood should be determined in the clinical evaluation of seafood reactions and specific shellfish/fish species tested to avoid unnecessary diet restriction. Autoinjectable epinephrine should be prescribed, and counseling regarding cross- contamination is an important component to seafood allergy management. More investigations are needed in the future to improve diagnostic methods and best practices in the clinical management of fish and shellfish allergy.

\section{Acknowledgment}

We thank Mrs Elvia Cortinas for editorial assistance.

\section{REFERENCES}

1. Ruethers T, Taki AC, Johnston EB, Nugraha R, Le TTK, Kalic T, et al. Seafood allergy: a comprehensive review of fish and shellfish allergens. Mol Immunol 2018;100:28-57.

2. Gupta RS, Warren CM, Smith BM, Jiang J, Blumenstock JA, Davis MM, et al Prevalence and severity of food allergies among US adults. JAMA Netw Open 2019;2:e185630.

3. Nowak-Wegrzyn A, Jarocka-Cyrta E, Moschione Castro A. Food proteininduced enterocolitis syndrome. J Investig Allergol Clin Immunol 2017;27: $1-18$.

4. Bahna SL. Not every seafood "allergy" is allergy! Ann Allergy Asthma Immunol 2016;117:458-61.

5. Acker WW, Plasek JM, Blumenthal KG, Lai KH, Topaz M, Seger DL, et al Prevalence of food allergies and intolerances documented in electronic health records. J Allergy Clin Immunol 2017;140:1587-1591.e1.

6. Tuano KTS, Davis CM. Oral allergy syndrome in shrimp and house dust mite allergies. J Allergy Clin Immunol Pract 2018;6:2163-4.

7. Thong BY, Arulanandam S, Tan SC, Tan TC, Chan GY, Tan JW, et al Shellfish/crustacean oral allergy syndrome among national service pre-enlistees in Singapore. Asia Pac Allergy 2018;8:e18.

8. Lopata AL, Zinn C, Potter PC. Characteristics of hypersensitivity reactions and identification of a unique $49 \mathrm{kd}$ IgE-binding protein (Hal-m-1) in abalone (Haliotis midae). J Allergy Clin Immunol 1997;100:642-8.

9. Turner PJ, Jerschow E, Umasunthar T, Lin R, Campbell DE, Boyle RJ. Fatal anaphylaxis: mortality rate and risk factors. J Allergy Clin Immunol Pract 2017; 5:1169-78.

10. Ramsey NB, Guffey D, Anagnostou K, Coleman NE, Davis CM. Epidemiology of anaphylaxis in critically ill children in the United States and Canada. J Allergy Clin Immunol Pract 2019;7:2241-9.

11. Ross MP, Ferguson M, Street D, Klontz K, Schroeder T, Luccioli S. Analysis of food-allergic and anaphylactic events in the National Electronic Injury Surveillance System. J Allergy Clin Immunol 2008;121:166-71.

12. Warren CM, Aktas ON, Gupta RS, Davis CM. Prevalence and characteristics of adult shellfish allergy in the United States. J Allergy Clin Immunol 2019;144 1435-8.e5.
13. Lopata AL, Jeebhay MF. Airborne seafood allergens as a cause of occupational allergy and asthma. Curr Allergy Asthma Rep 2013;13:288-97.

14. Shek LP, Cabrera-Morales EA, Soh SE, Gerez I, Ng PZ, Yi FC, et al. A population-based questionnaire survey on the prevalence of peanut, tree nut, and shellfish allergy in 2 Asian populations. J Allergy Clin Immunol 2010;126: 324-31.e1-e7.

15. Leung TF, Yung E, Wong YS, Lam CW, Wong GW. Parent-reported adverse food reactions in Hong Kong Chinese pre-schoolers: epidemiology, clinical spectrum and risk factors. Pediatr Allergy Immunol 2009;20:339-46.

16. Le TTK, Nguyen DH, Vu ATL, Ruethers T, Taki AC, Lopata AL. A crosssectional, population-based study on the prevalence of food allergies among children in two different socio-economic regions of Vietnam. Pediatr Allergy Immunol 2019;30:348-55.

17. Zotova V, Clarke AE, Chan ES, Asai Y, Chin R, Van Lambalgen C, et al Low resolution rates of seafood allergy. J Allergy Clin Immunol Pract 2019;7: 690-2.

18. Kalic T, Morel-Codreanu F, Radauer C, Ruethers T, Taki AC, Swoboda I, et al. Patients allergic to fish tolerate ray based on the low allergenicity of its parvalbumin. J Allergy Clin Immunol Pract 2019;7:500-508.e11.

19. Lopata AL, Kleine-Tebbe J, Kamath SD. Allergens and molecular diagnostics of shellfish allergy: part 22 of the Series Molecular Allergology. Allergo J Int 2016;25:210-8

20. Kamath SD, Johnston EB, Iyer S, Schaeffer PM, Koplin J, Allen K, et al. IgE reactivity to shrimp allergens in infants and their cross-reactivity to house dust mite. Pediatr Allergy Immunol 2017;28:703-7.

21. Ruethers T, Taki AC, Nugraha R, Cao TT, Koeberl M, Kamath SD, et al. Variability of allergens in commercial fish extracts for skin prick testing. Allergy 2019;74:1352-63.

22. Willette DA, Simmonds SE, Cheng SH, Esteves S, Kane TL, Nuetzel H, et al. Using DNA barcoding to track seafood mislabeling in Los Angeles restaurants. Conserv Biol 2017;31:1076-85.

23. Nugraha R, Kamath SD, Johnston E, Zenger KR, Rolland JM, O'Hehir RE, et al. Rapid and comprehensive discovery of unreported shellfish allergens using large-scale transcriptomic and proteomic resources. J Allergy Clin Immunol 2018;141:1501-1504.e8.

24. Kamath SD, Rahman AM, Voskamp A, Komoda T, Rolland JM, O'Hehir RE, et al. Effect of heat processing on antibody reactivity to allergen variants and fragments of black tiger prawn: a comprehensive allergenomic approach. Mol Nutr Food Res 2014:58:1144-55.

25. Kamath SD, Abdel Rahman AM, Komoda T, Lopata AL. Impact of heat processing on the detection of the major shellfish allergen tropomyosin in crustaceans and molluscs using specific monoclonal antibodies. Food Chem 2013; 141:4031-9.

26. Chokshi NY, Sicherer SH. Interpreting IgE sensitization tests in food allergy. Expert Rev Clin Immunol 2016;12:389-403.

27. Van Do T, Elsayed S, Florvaag E, Hordvik I, Endresen C. Allergy to fish parvalbumins: studies on the cross-reactivity of allergens from 9 commonly consumed fish. J Allergy Clin Immunol 2005;116:1314-20.

28. Kuehn A, Hilger C, Lehners-Weber C, Codreanu-Morel F, Morisset M, MetzFavre C, et al. Identification of enolases and aldolases as important fish allergens in cod, salmon and tuna: component resolved diagnosis using parvalbumin and the new allergens. Clin Exp Allergy 2017;43:811-22.

29. Kuehn A, Fischer J, Hilger C, Sparla C, Biedermann T, Hentges F. Correlation of clinical monosensitivity to cod with specific IgE to enolase and aldolase. Ann Allergy Asthma Immunol 2014;113:670-671.e2.

30. Kobayashi Y, Akiyama H, Huge J, Kubota H, Chikazawa S, Satoh T, et al. Fish collagen is an important panallergen in the Japanese population. Allergy 2016; 71:720-3.

31. Nieuwenhuizen NE, Lopata AL. Allergic reactions to Anisakis found in fish. Curr Allergy Asthma Rep 2014;14:455.

32. Moneo I, Carballeda-Sangiao N, González-Muñoz M. New perspectives on the diagnosis of allergy to Anisakis spp. Curr Allergy Asthma Rep 2017;17:27.

33. Kandyil RM, Davis CM. Shellfish allergy in children. Pediatr Allergy Immunol 2009;20:408-14.

34. Calvani M, Di Lallo D, Polo A, Spinelli A, Zappalà D, Zicari AM. Hospitalizations for pediatric anaphylaxis. Int J Immunopathol Pharmacol 2008;21:977-83.

35. Gupta RS, Springston EE, Warrier MR, Smith B, Kumar R, Pongracic J, et al. The prevalence, severity, and distribution of childhood food allergy in the United States. Pediatrics 2011;128:e9-17.

36. Mullins RJ, Wainstein BK, Barnes EH, Liew WK, Campbell DE. Increases in anaphylaxis fatalities in Australia from 1997 to 2013. Clin Exp Allergy 2016; 46:1099-110.

37. Woo CK, Bahna SL. Not all shellfish 'allergy' is allergy! Clin Transl Allergy 2011;1:1-7. 
38. Roberts G, Lack G. Relevance of inhalational exposure to food allergens. Curr Opin Allergy Clin Immunol 2003;3:211-5.

39. Ramirez DA Jr, Bahna SL. Food hypersensitivity by inhalation. Clin Mol Allergy 2009;7:4.

40. Desjardins A, Malo JL, L'Archeveque J, Cartier A, McCants M, Lehrer SB Occupational IgE-mediated sensitization and asthma caused by clam and shrimp. J Allergy Clin Immunol 1995;96:608-17.

41. Popescu FD. Cross-reactivity between aeroallergens and food allergens. World J Methodol 2015;5:31-50

42. Bertelsen RJ, Svanes $\varnothing$, Madsen AM, Hollund BE, Kirkeleit J, Sigsgaard T, et al. Pulmonary illness as a consequence of occupational exposure to shrimp shell powder. Environ Res 2016;148:491-9.

43. Jeebhay MF, Moscato G, Bang BE, Folletti I, Lipińska-Ojrzanowska A, Lopata AL, et al. Food processing and occupational respiratory allergy-a EAACI Position Paper. Allergy 2019;74:1852-71.

44. Ayuso R, Lehrer SB, Reese G. Identification of continuous, allergenic regions of the major shrimp allergen Pen a 1 (tropomyosin). Int Arch Allergy Immunol 2002;127:27-37.

45. Khan F, Orson F, Ogawa Y, Parker C, Davis CM. Adult seafood allergy in the Texas Medical Center: a 13-year experience. Allergy Rhinol (Providence) 2011;2 e71-7.

46. Torres-Borrego J, Martinez-Cuevas JF, Tejero-Garcia J. Cross reactivity between fish and shellfish. Allergol Immunopathol 2003:31:146-51.

47. Lopata AL, Lehrer SB. New insights into seafood allergy. Curr Opin Allergy Clin Immunol 2009;9:270-7.

48. Sicherer SH, Sampson HA. Food Allergy. J Allergy Clin Immunol 2010;125: S116-25.

49. Abramovitch JB, Kamath S, Varese N, Zubrinich C, Lopata AL, O'Hehir RE, et al. IgE reactivity of blue swimmer crab Portunus pelagicus tropomyosin, Por p 1, and other allergens: cross-reactivity with black Tiger prawn and effects of heating. PLoS One 2013;8:e67487.

50. Abramovitch JB, Lopata AL, O'Hehir RE, Rolland JM. Effect of therma processing on $\mathrm{T}$ cell reactivity of shellfish allergens-discordance with $\mathrm{IgE}$ reactivity. PLoS One 2017;12:e0173549.

51. Rolland JM, Varese NP, Abramovitch JB, Anania J, Nugraha R, Kamath S, et al Effect of heat processing on IgE reactivity and cross-reactivity of tropomyosin and other allergens of Asia-Pacific mollusc species: identification of novel Sydney Rock Oyster tropomyosin Sac g 1. Mol Nutr Food Res 2018:e1800148.

52. Chapman JA, Bernstein IL, Lee RE, Oppenheimer J, Nicklas RA, Portnoy JM, et al. Food allergy: a practice parameter. Ann Allergy Asthma Immunol 2006 96:S1-68.

53. Sicherer SH, Muñoz-Furlong A, Sampson HA. Prevalence of seafood allergy in the United States determined by a random telephone survey. J Allergy Clin Immunol 2004;114:159-65.

54. Tong WS, Yuen AW, Wai CY, Leung NY, Chu KH, Leung PS. Diagnosis of fish and shellfish allergies. J Asthma Allergy 2018;11:247-60.

55. Liccardi G, D’Amato G, Canonica GW, Salzillo A, Piccolo A, Passalacqua G. Systemic reactions from skin testing: literature review. J Investig Allergol Clin Immunol 2006;16:75-8.

56. Norrman G, Falth-Magnusson K. Adverse reactions to skin prick testing in children — prevalence and possible risk factors. Pediatr Allergy Immunol 2009; 20:273-8

57. Codreanu F, Moneret-Vautrin DA, Morisset M, Guénard L, Rancé F, Kanny G, et al The risk of systemic reactions to skin prick-tests using food allergens: CICBAA data and literature review. Eur Ann Allergy Clin Immunol 2006;38:52-4.

58. Haktanir AM, Orhan F. Anaphylaxis after prick-to-prick test with fish. Pediatr Int 2016;58:503-5.

59. Pitsios C, Dimitriou A, Stefanaki EC, Kontou-Fili K. Anaphylaxis during skin testing with food allergens in children. Eur J Pediatr 2010;169:613-5.

60. Devenney I, Faith-Magnusson K. Skin prick tests may give generalized allergic reactions in infants. Ann Allergy Asthma Immunol 2000;85:457-60.

61. Novembre E, Bernardini R, Bertini G, Massai G, Vierucci A. Skin prick test induced anaphylaxis. Allergy 1995;50:511-3.

62. Bagg A, Chacko T, Lockey R. Reactions to prick and intradermal skin tests Ann Allergy Asthma Immunol 2009;102:400-2.

63. Schulkes KJ, Klemans RJ, Knigge L, de Bruin-Weller M, BruijnzeelKoomen CA, Marknell deWitt A. Specific IgE to fish extracts does not predict allergy to specific species within an adult fish allergic population. Clin Trans Allergy 2014;4:27.

64. Bernhisel-Broadbent J, Scanlon SM, Sampson HA. Fish hypersensitivity, I in vitro and oral challenge results in fish-allergic patients. J Allergy Clin Immunol 1992;89:730-7.

65. Helbling A, Haydel R Jr, McCants ML, Musmand JJ, El-Dahr J, Lehrer SB. Fish allergy: is cross-reactivity among fish species relevant? Double-blind placebo-controlled food challenge studies of fish allergic adults. Ann Allergy Asthma Immunol 1999;83:517-23

66. Pascual C, Martin Esteban M, Crespo JF. Fish allergy: evaluation of the importance of cross-reactivity. J Pediatr 1992;121:S29-34.

67. van Hage M, Hamsten C, Valenta R. ImmunoCAP assays: pros and cons in allergology. J Allergy Clin Immunol 2017;140:974-7.

68. Yang AC, Arruda LK, Santos AB, Barbosa MC, Chapman MD, Galvão CE, et al. Measurement of IgE antibodies to shrimp tropomyosin is superior to skin prick testing with commercial extract and measurement of IgE to shrimp for predicting clinically relevant allergic reactions after shrimp ingestion. J Allergy Clin Immunol 2010;125:872-8.

69. Tuano KTS, Anvari S, Hanson IC, Hajjar J, Seeborg F, Noroski LM, et al. Improved diagnostic clarity in shrimp allergic non-dust-mite sensitized patients. Allergy Asthma Proc 2018;39:377-83.

70. Johnston EB, Kamath SD, Iyer SP, Pratap K, Karnaneedi S, Taki AC, et al. Defining specific allergens for improved component-resolved diagnosis of shrimp allergy in adults. Mol Immunol 2019;112:330-7.

71. Song Y, Wang J, Leung N, Wang LX, Lisann L, Sicherer SH, et al. Correlations between basophil activation, allergen-specific IgE with outcome and severity of oral food challenges. Ann Allergy Asthma Immunol 2015;114:319-26.

72. Gámez C, Sánchez-García S, Ibáñez MD, López R, Aguado E, López E, et al. Tropomyosin IgE-positive results are a good predictor of shrimp allergy. Allergy 2011;66:1375-83.

73. Farioli L, Losappio LM, Giuffrida MG, Pravettoni V, Micarelli G, Nichelatti M, et al. Mite-induced asthma and IgE levels to shrimp, mite, tropomyosin, arginine kinase, and Der p 10 are the most relevant risk factors for challenge-proven shrimp allergy. Int Arch Allergy Immunol 2017;174:133-43.

74. Faber MA, Pascal M, El Kharbouchi O, Sabato V, Hagendorens MM, Decuyper II, et al. Shellfish allergens: tropomyosin and beyond. Allergy 2017;72:842-8.

75. Pascal M, Grishina G, Yang AC, Sánchez-García S, Lin J, Towle D, al Iet. Molecular diagnosis of shrimp allergy: efficiency of several allergens to predict clinical reactivity. J Allergy Clin Immunol Pract 2015:3:521-529.e10.

76. Pali-Schöll I, Meinlschmidt P, Larenas-Linnemann D, Purschke B, Hofstetter G, Rodríguez-Monroy FA, et al. Edible insects: cross-recognition of IgE from crustacean- and house dust mite allergic patients, and reduction of allergenicity by food processing. World Allergy Organ J 2019;12:100006.

77. Matricardi PM, Kleine-Tebbe J, Hoffmann HJ, Valenta R, Hilger C, Hofmaier S, et al. EAACI molecular allergology user's guide. Pediatr Allergy Immunol 2016;27:1-250.

78. Ballmer-Weber BK, Beyer K. Food challenges. J Allergy Clin Immunol 2018; 141:69-71.e2.

79. Nowak-Wegrzyn A, Assa'ad AH, Bahna SL, Bock SA, Sicherer SH, Teuber SS, Adverse Reactions to Food Committee of American Academy of Allergy, Asthma \& Immunology. Work group report: oral food challenge testing. J Allergy Clin Immunol 2009;123:S365-83.

80. Lieberman P, Nicklas RA, Randolph C, Oppenheimer J, Bernstein D, Bernstein J, et al. Anaphylaxis-practice parameter update 2015. Ann Allergy Asthma Immunol 2015;115:341-84.

81. Sørensen M, Kuehn A, Mills ENC, Costello CA, Ollert M, Småbrekke L, et al. Cross-reactivity in fish allergy: a double-blind, placebo-controlled foodchallenge trial. J Allergy Clin Immunol 2017;140:1170-2.

82. Mourad AA, Bahna SL. Fish-allergic patients may be able to eat fish. Expert Rev Clin Immunol 2015;11:419-30.

83. Trevino S. Fish and shellfish poisoning. Clin Lab Sci 1998;11:309-14.

84. Feng C, Teuber S, Gershwin ME. Histamine (scombroid) fish poisoning: a comprehensive review. Clin Rev Allergy Immunol 2016;50:64-9.

85. Friedman MA, Fernandez M, Backer LC, Dickey RW, Bernstein J, Schrank K, et al. An updated review of ciguatera fish poisoning: clinical, epidemiological, environmental, and public health management. Mar Drugs 2017;15.

86. Traylor J, Malik A, Goldstein S. Histamine (scombroid toxicity, mahi-mahi flush) toxicity. Treasure Island, FL: StatPearls Publishing; 2019.

87. Kipping R, Eastcott H, Sarangi J. Tropical fish poisoning in temperate climates: food poisoning from ciguatera toxin presenting in Avonmouth. J Public Health (Oxf) 2006:28:343-6.

88. Farabegoli F, Blanco L, Rodríguez LP, Vieites JM, Cabado AG. Phycotoxins in marine shellfish: origin, occurrence and effects on humans. Mar Drugs 2018:16:E188.

89. Mattiucci S, Cipriani P, Levsen A, Paoletti M, Nascetti G. Molecular epidemiology of Anisakis and anisakiasis: an ecological and evolutionary road map. Adv Parasitol 2018;99:93-263.

90. Nieuwenhuizen NE. Anisakis-immunology of a foodborne parasitosis. Parasite Immunol 2016;38:548-57.

91. La Bella G, Martella V, Basanisi MG, Nobili G, Terio V, La Salandra G. Foodborne viruses in shellfish: investigation on norovirus and HAV presence in Apulia (SE Italy). Food Environ Virol 2017;9:179-86. 